\title{
Pericecal Hernia Presenting as Acute Appendicitis
}

\author{
Anupam K. Gupta ${ }^{1}$, Michael P. Kucharik ${ }^{2}$, Arye Lavin ${ }^{2}$, Miguel Lopez-Viego ${ }^{3}$ \\ 1. Surgery, Charles E. Schmidt College of Medicine, Florida Atlantic University, Boca Raton, USA 2. Internal Medicine, \\ Charles E. Schmidt College of Medicine, Florida Atlantic University, Boca Raton, USA 3. General \& Vascular Surgery, \\ Bethesda Hospital East, Boynton Beach, USA
}

Corresponding author: Michael P. Kucharik, mkucharik2016@health.fau.edu

\begin{abstract}
We would like to report an unusual case of a pericecal hernia in a 93-year-old female. The patient did not report a history of previous abdominal surgery and presented with acute abdominal pain, constipation, nausea, and vomiting. Diagnosis was made with computerized tomography and laparoscopy was performed, which was significant for loops of small bowel in the pericecal region in a defect of peritoneum. The small bowel loops were mobilized back in the intraperitoneal location and the defect was closed to prevent further herniation. Our case is an extremely rare presentation of a rare condition, as there have only been five reported cases of pericecal hernias that required immediate surgical intervention and outlined explicit details of the surgical procedure. Pericecal hernias are unusual occurrences and occur more frequently in older women. Since the clinical signs and symptoms mimic acute appendicitis, delays in diagnosis are common. Thus, this case highlights the importance of suspecting strangulated internal hernias in patients with signs and symptoms of acute appendicitis to prevent significant morbidity and mortality.
\end{abstract}

Categories: Gastroenterology, General Surgery

Keywords: hernia, pericecal, internal hernia, acute appendicitis, paracecal hernia, pericecal hernia

\section{Introduction}

Hernias can be broadly categorized as internal and external. An internal hernia is the protrusion of visceral contents through a congenital or acquired opening within the peritoneal cavity, whereas external hernias occur through an opening in the abdominal wall [1]. Internal hernias comprise less than $1 \%$ of all hernias, but constitute up to $5.8 \%$ of all cases of small bowel obstructions [2]. If left untreated, internal hernias are associated with a mortality rate that exceeds $50 \%$. Among the subsets of internal hernias, pericecal hernias comprise approximately $13 \%$ of all cases [2]. Early diagnosis of this rare condition can aid in laparoscopic management and prevent significant morbidity and mortality [3].

Both hernias and appendicitis can present with abdominal pain. The pain associated with appendicitis is classically initially dull, migratory, and periumbilical, but becomes sharp in the right lower quadrant once the parietal peritoneum is irritated by a distended and inflamed appendix. With a lifetime risk of $8.6 \%$ in males and $6.7 \%$ in females, appendicitis is a common pathology that can mask infrequent causes of right

Received 01/20/2020 Review began $01 / 23 / 2020$ Review ended 02/02/2020 Published 02/04/2020

\section{() Copyright 2020}

Gupta et al. This is an open access article distributed under the terms of the Creative Commons Attribution License CC-BY 4.0., which permits unrestricted use, distribution, and reproduction in any medium, provided the original author and source are credited. lower quadrant abdominal pain, such as a strangulated pericecal hernia [4].

\section{Case Presentation}

We would like to report a 93-year-old female with no previous abdominal surgery, presenting with a threeday history of constipation and one-day history of abdominal pain, nausea and vomiting. The abdominal pain was described as sharp and located in the right lower quadrant. On presentation, the patient was afebrile and did not complain of recent chills, night sweats, melena, weight loss, or previously altered bowel habits. Her past medical history was significant for hyperlipidemia and gastroesophageal reflux disease. She had no previous surgeries and her medication list included simvastatin and ranitidine. The patient's vital signs were notable for a temperature of $99.4^{\circ} \mathrm{F}$, heart rate of $98 \mathrm{bpm}$, blood pressure $110 / 90 \mathrm{~mm} \mathrm{Hg}$, respiratory rate of 18 breaths per min, and an oxygen saturation of more than $95 \%$ on room air. Clinically, abdomen was soft, but distended with tenderness on palpation in the right lower quadrant with sluggish bowel sounds.

At this point, due to the patient's history and nature of the abdominal pain, our leading diagnosis was acute appendicitis followed by small bowel obstruction with a possible corresponding hernia. Since the patient had a negative past abdominal surgical history, adhesions would be an unlikely cause of small bowel obstruction. Other causes of right lower quadrant abdominal pain such as nephrolithiasis and ischemic bowel were less likely due to the absence of hematuria or hematochezia/melena.

Her routine blood work was significant for an elevated white count to $12,000 / \mathrm{mL}$ with $89 \%$ neutrophilia, hemoglobin $12.9 \mathrm{~g} / \mathrm{dL}$, hematocrit of $30 \%$, platelet count of $150,000 / \mathrm{mL}$ and basic electrolyte profile showed sodium of $140 \mathrm{mEq} / \mathrm{mL}$, potassium of $3.7 \mathrm{mEq} / \mathrm{mL}$, blood urea nitrogen of $37 \mathrm{mg} / \mathrm{dL}$, creatinine of $1.1 \mathrm{mg} / \mathrm{dL}$, and C-reactive protein of $5.5 \mathrm{mg} / \mathrm{L}$. A noncontrast computed tomography $(\mathrm{CT})$ scan of the abdomen and 


\section{Cureus}

pelvis was performed to further investigate. This revealed small-bowel loops in the right lower quadrant lateral to the ascending colon. The loop of bowel appeared distended and was associated with some mesenteric fat stranding (Figures 1,2).

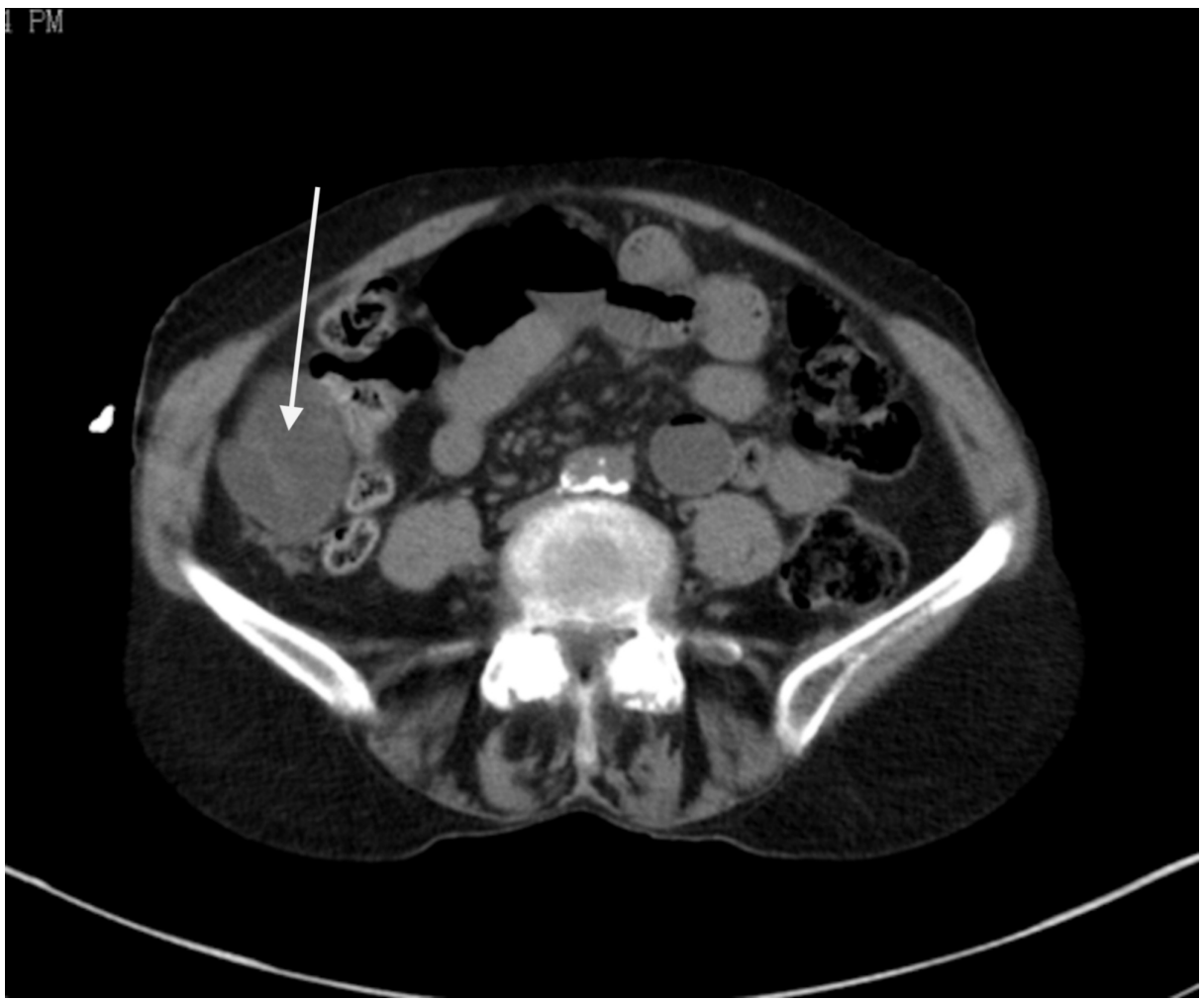

FIGURE 1: Dilated small bowel loop lateral to cecum in the right paracolic gutter.

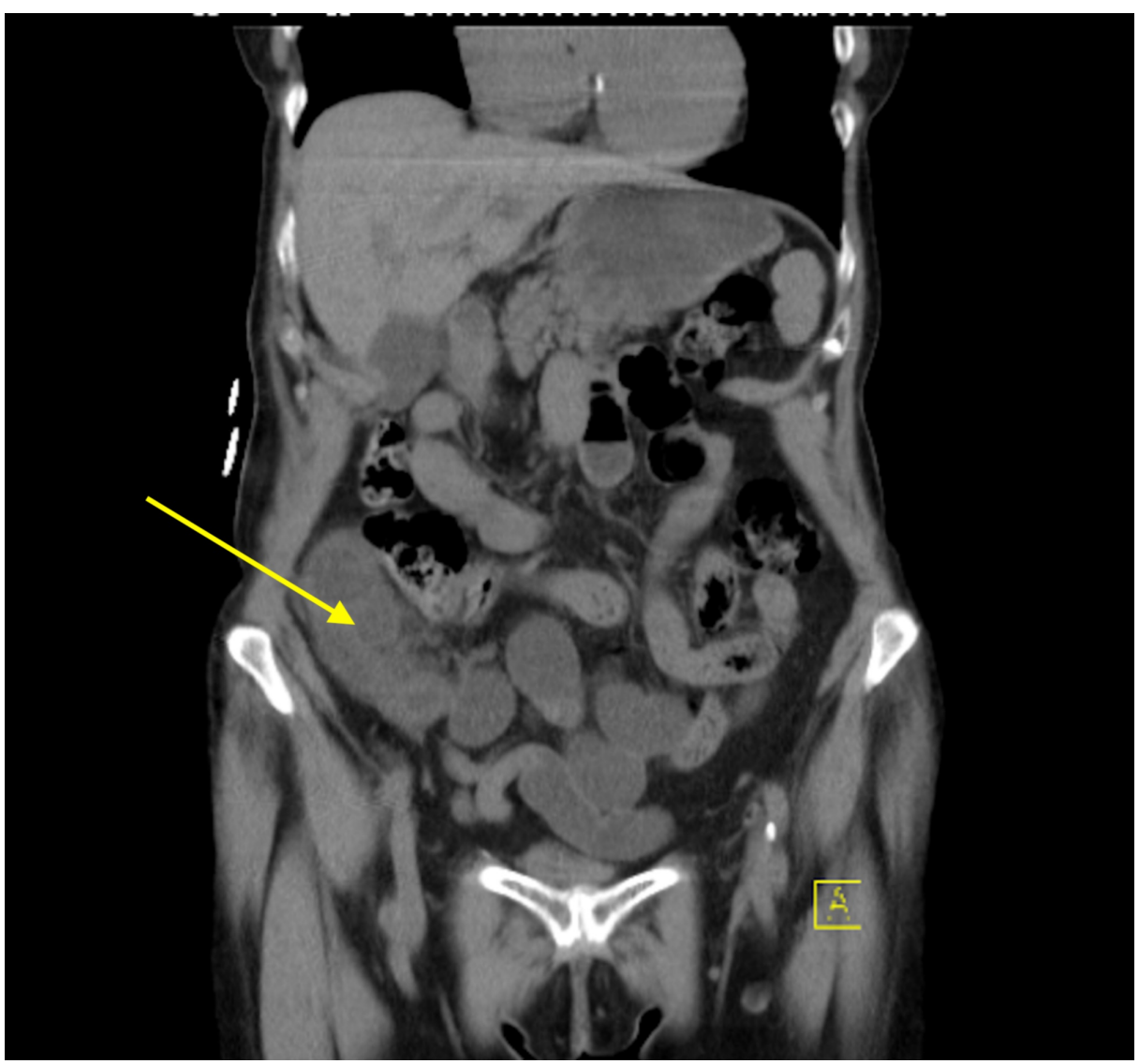




\section{Cureus}

\section{FIGURE 2: Small bowel loop lateral to cecum.}

After fluid resuscitation and bowel rest, the patient was considered for surgery as she continued to complain of increasing pain in right lower quadrant, which was not relieved with ketorolac.

The patient was taken to the operating room and a diagnostic laparoscopy was performed using a 10-mm video port at the umbilicus. An additional midline 5-mm port was placed in the suprapubic region. Loops of small bowel were visualized in the pericecal region in a defect of peritoneum. The small bowel loops were mobilized back in the intraperitoneal location using a grasper and blunt dissection. The peritoneal defect was identified (Figure 3) and this natural orifice was subsequently overlapped with the surrounding peritoneum and closed with vicryl tackers to prevent further herniation. The bowel loops appeared congested and edematous, however, were viable in nature so no resection anastomosis was performed.

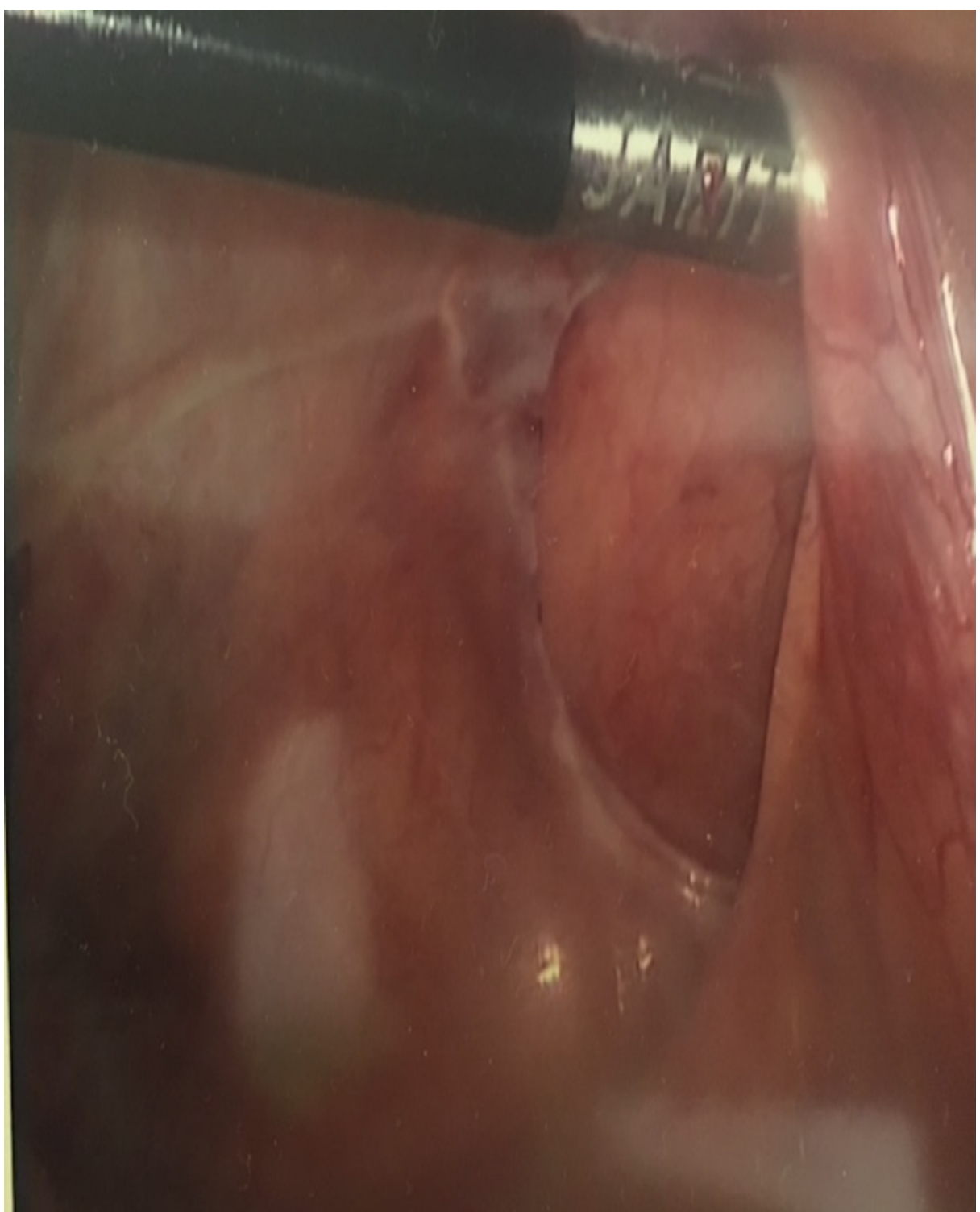

FIGURE 3: Intraoperative picture showing the pericecal defect which was subsequently closed with vicryl tackers.

The patient withstood the procedure well and had a normal postoperative course. The patient was tolerating diet and ambulatory on postoperative day 1 . On postoperative day 2 , the patient was subsequently discharged with an in-office follow-up scheduled for postoperative day 7 . On postoperative day 7 , the patient's surgical incisions were dry, clean, and intact. Her bowel habits returned to normal and she denied nausea, abdominal pain, fever, chills, melena, hematochezia, or abdominal pain. 


\section{Discussion}

Internal hernias can result from natural orifices or those made from procedures, such as Roux-en-Y gastric bypass [2]. Most common natural orifices include paraduodenal (53\%), pericecal (13\%), foramen of Winslow (8\%), transmesenteric (8\%), and intersigmoid (6\%) [3, 5]. Pericecal hernias are uncommon and mimic acute appendicitis in initial stages with pain and nausea followed by small bowel obstruction in the later stages [2]. The pericecal recesses are formed around the fifth month of gestation when the bowel loops return to the abdominal cavity [3]. There are four defined pericecal recesses: superior ileocecal, inferior ileocecal, retrocecal, and paracolic sulci [2]. When obstructed, patients complain of obstipation and right lower quadrant tenderness [5].

Radiograph imaging, specifically non-contrast CT scans, reveals loops of bowel, usually posterolateral to the cecum and right paracolic gutter. Also present can be signs of small bowel obstruction, such as air fluid levels, dilated loops of small bowel, and a transition point [3]. Early diagnosis and use of laparoscopy can help reduce the hernia and minimize morbidity.

A literature review on PubMed including the terms "pericecal hernia" and "paracecal hernia" yielded 27 and 24 matches, respectively. Articles that did not provide surgical details or utilize urgent surgical intervention were excluded from our literature review. One manuscript reported three cases of pericecal hernia in a series of 533 cases of small bowel obstruction [6]. Among the remaining 13 cases, the demographics included a mean age of 69 years, with eight female and five male patients (Table 1). Only three patients had prior surgical history, two of which underwent appendectomy near the pericecal region. Eight of these patients were managed by exploratory laparotomy, while five were managed laparoscopically (Table 1) [7-17].

\begin{tabular}{|c|c|c|c|c|}
\hline Serial No. & Age/Sex & Past surgical history & Surgery & Source \\
\hline 1 & $88 / F$ & Unknown & Exploratory laparotomy & (Kumar et al., 2015 [15]) \\
\hline 2 & 92/M & Cholecystectomy & Laparoscopic & (Ogami et al., 2016 [3]) \\
\hline 3 & 65/M & None & Laparoscopic & (Sasaki et al., 2016 [16]) \\
\hline 4 & $34 / \mathrm{M}$ & None & Exploratory laparotomy & (Kleyman et al., 2013 [10]) \\
\hline 5 & $69 / M$ & None & Exploratory laparotomy & (Lu et al., 2017 [11]) \\
\hline 6 & $67 / F$ & Appendectomy & Exploratory laparotomy & (Lu et al., 2017 [11]) \\
\hline 7 & $70 / F$ & None & Exploratory laparotomy & (Nishi et al., 2011 [13]) \\
\hline 8 & $84 / F$ & None & Exploratory laparotomy & (Jang et al., 2011 [8]) \\
\hline 9 & 63/M & Unknown & Exploratory laparotomy & (Shibuya et al., 2010 [17]) \\
\hline 10 & 43/F & Unknown & Laparoscopic & (Kabashima et al., 2010 [9]) \\
\hline 11 & $74 / F$ & Laparoscopic appendectomy & Laparoscopic to minilaparotomy & (Hirokawa et al., 2007 [7]) \\
\hline 12 & $59 / F$ & Unknown & Exploratory laparotomy & (Molto Aguado et al., 2007 [12]) \\
\hline 13 & 90/F & Unknown & Laparoscopic & (Omori et al., 2003 [14]) \\
\hline
\end{tabular}

TABLE 1: Published cases of pericecal hernias treated with urgent surgical intervention.

When comparing the aforementioned cases with our case, our patient's presentation is particularly notable because of her age, lack of past surgical history, and surgical method. According to our literature review, there were just two other nonagenarian patients that suffered from this condition [3,13]. Moreover, our patient was the only nonagenarian patient to present with a negative past surgical history and without risk factors for hernia including pregnancy, recent weight lifting, constipation, or weight gain.

Additionally, immediate diagnostic imaging allowed our patient to be managed with minimally invasive laparoscopic surgery. Based on our literature review, the nonspecific signs and symptoms of strangulated pericecal hernias delayed diagnostic imaging, which ultimately resulted in an exploratory laparotomy in a majority of cases. Thus, our case can be utilized as a guide for the early diagnosis and management of patients with potential strangulated internal hernias.

\section{Conclusions}


Pericecal hernia is an unusual occurrence and is seen to occur more frequently in older women. The clinical signs and symptoms often mimic acute appendicitis, which typically causes a delay in diagnosis. Clinical findings are often insufficient to make a diagnosis. Early diagnosis can be made with imaging like computed tomography. In patients, early laparoscopy can help confirm diagnosis and reduce the internal hernia. The internal hernial orifice should be closed or enlarged to prevent further herniation. Delay in diagnosis can result in hernia getting complicated needing an exploratory laparotomy and prolonged morbidity.

\section{Additional Information \\ Disclosures}

Human subjects: Consent was obtained by all participants in this study. Conflicts of interest: In compliance with the ICMJE uniform disclosure form, all authors declare the following: Payment/services info: All authors have declared that no financial support was received from any organization for the submitted work. Financial relationships: All authors have declared that they have no financial relationships at present or within the previous three years with any organizations that might have an interest in the submitted work. Other relationships: All authors have declared that there are no other relationships or activities that could appear to have influenced the submitted work.

\section{References}

1. Lassandro F, Iasiello F, Pizza NL, Valente T, di Santo Stefano MLM, Grassi R, Muto R: Abdominal hernias: radiological features. World J Gastrointest Endosc. 2011, 3:110-117. 10.4253/wige.v3.i6.110

2. Martin LC, Merkle EM, Thompson WM: Review of internal hernias: radiographic and clinical findings . Am J Roentgenol. 2006, 186:703-717. 10.2214/AJR.05.0644

3. Ogami T, Honjo H, Kusanagi H: Pericecal hernia manifesting as a small bowel obstruction successfully treated with laparoscopic surgery. J Surg Case Rep. 2016, 2016:rjw020. 10.1093/jscr/rjw020

4. Snyder MJ, Guthrie M, Cagle S: Acute appendicitis: efficient diagnosis and management. Am Fam Physician. 2018, 98:25-33.

5. Osadchy A, Keidar A, Zissin R: Small bowel obstruction due to a paracecal hernia: computerized tomography diagnosis. Emerg Radiol. 2005, 11:239-241. 10.1007/s10140-004-0397-5

6. Sciacca P, Bertolini R, Borrello M, Bargigli R, Marcarone Palmieri R: Intestinal obstruction caused by paracecal hernia. 3 case reports and review of the literature. (Article in Italian). Minerva Chir. 1997, 52:983988.

7. Hirokawa T, Hayakawa T, Tanaka M, Okada Y, Sawai H, Takeyama H, Manabe T: Laparoscopic surgery for diagnosis and treatment of bowel obstruction: case report of paracecal hernia. Med Sci Monit. 2007, 13:7982.

8. Jang EJ, Cho SH, Kim DD: A case of small bowel obstruction due to a paracecal hernia . J Korean Soc Coloproctol. 2011, 27:41-43. 10.3393/jksc.2011.27.1.41

9. Kabashima A, Ueda N, Yonemura Y, et al.: Laparoscopic surgery for the diagnosis and treatment of a paracecal hernia repair: report of a case. Surg Today. 2010, 40:373-375. 10.1007/s00595-009-4039-0

10. Kleyman S, Ashraf S, Daniel S, Ananthan D, Sanni A, Khan F: Pericecal hernia: a rare form of internal hernias. J Surg Case Rep. 2013, 2013:rjs021. 10.1093/jscr/rjs021

11. Lu HC, Wang J, Tsang YM, Tseng HS, Li YW: Pericecal hernia: a report of two cases and survey of the literature. Clin Radiol. 2002, 57:855-858.

12. Molto Aguado M, Gonzalez Valverde FM, Barreras Mateos JA, Vázquez Rojas JL: Small intestinal strangulation due to a primary internal paracecal hernia. Hernia. 2007, 11:457-458. 10.1007/s10029-0070210-y

13. Nishi T, Tanaka Y, Kure T: A case of pericecal hernia with a hernial orifice located on the lateral side of the cecum. Tokai J Exp Clin Med. 2011, 36:71-74.

14. Omori H, Asahi H, Inoue Y, Irinoda T, Saito K: Laparoscopic paracecal hernia repair. J Laparoendosc Adv Surg Tech A. 2003, 13:55-57. 10.1089/109264203321235494

15. Kumar S, Dikshit P, Bhaduri S, Sattavan S: Gangrenous appendicitis: a rare presentation of pericecal hernia; case report and review of the literature. Bull Emerg Trauma. 2015, 3:144-147.

16. Sasaki K, Kawasaki, Abe H, Nagai H, Yoshimi F: Retrocecal hernia successfully treated with laparoscopic surgery: a case report and literature review of 15 cases in Japan. Int J Surg Case Rep. 2016, 18:45-47. 10.1016/j.ijscr.2015.11.022

17. Shibuya H, Ishihara S, Akahane T, et al.: A case of paracecal hernia . Int Surg. 2010, 95:277-280. 